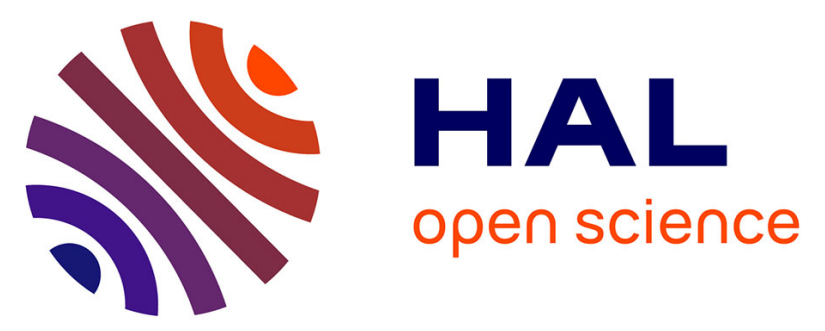

\title{
Filterless millimetre-wave optical generation using optical phase modulators without DC bias
}

\author{
Rabiaa Guemri, Frédéric Lucarz, Daniel Bourreau, Camilla Kärnfelt,
} Jean-Louis de Bougrenet de La Tocnaye, Trevor Hall

\section{To cite this version:}

Rabiaa Guemri, Frédéric Lucarz, Daniel Bourreau, Camilla Kärnfelt, Jean-Louis de Bougrenet de La Tocnaye, et al.. Filterless millimetre-wave optical generation using optical phase modulators without DC bias. PRIME 2014: 10th Conference on Ph.D Research In Microelectronics and Electronics, Jun 2014, Grenoble, France. pp.1 - 4, 10.1109/PRIME.2014.6872658 • hal-01208290

\section{HAL Id: hal-01208290 \\ https://hal.science/hal-01208290}

Submitted on 2 Oct 2015

HAL is a multi-disciplinary open access archive for the deposit and dissemination of scientific research documents, whether they are published or not. The documents may come from teaching and research institutions in France or abroad, or from public or private research centers.
L'archive ouverte pluridisciplinaire HAL, est destinée au dépôt et à la diffusion de documents scientifiques de niveau recherche, publiés ou non, émanant des établissements d'enseignement et de recherche français ou étrangers, des laboratoires publics ou privés. 


\section{Filterless millimetre-wave optical generation using optical phase modulators without DC bias}

\author{
Rabiaa Guemri, Frédéric Lucarz, Daniel Bourreau, \\ Camilla Kärnfelt, Jean-Louis de Bougrenet de la \\ Tocnaye \\ Optics Department, Télécom Bretagne \\ Technopôle Brest-Iroise CS 83818 \\ 29238 Brest Cedex 3, France
}

E-mail : Rabiaa.Guemri@telecom-bretagne.eu

\begin{abstract}
A tunable millimetre-wave generator using optical phase modulators with no DC bias and no filters (neither RF nor optical filters) is proposed in this paper. A $60 \mathrm{GHz}$ RF signal is optically generated by multiplying the frequency of an input RF signal at $7.5 \mathrm{GHz}$ by a factor of 8 . The electrical suppression ratio is around $50 \mathrm{~dB}$ as shown by simulations.
\end{abstract}

Keywords-millimetre-wave, optical generation, phase modulators, radio-over-fibre

\section{INTRODUCTION}

The evolution of millimetre-wave communications requires efficient methods to generate and distribute high-frequency signals in wireless access networks. Electrical generation of millimetre-wave (mm-wave) signals suffers from limitations due to high propagation losses in the air, as well as in waveguides. Besides, electrical techniques are not particularly well adapted to fibre-supported wireless networks. Over the last decade, many research activities have been conducted to optically generate and transport mm-wave signals [1] to take advantage of huge bandwidths and low attenuations of optical fibres in the context of Radio-over-Fibre (RoF) [2-5]. The concept of optical generation is to heterodyne two optical signals spectrally separated from each other by the required mm-wave frequency, so as to generate an RF signal at the desired frequency upon photo-detection. A plurality of photonic techniques has been proposed so far, such as: dualmode lasers [6], optical phase locking [7], optical injection locking [8], optical injection phase locking [9], four-wave mixing [10-11] and stimulated Brillouin scattering [12]. The most attractive solution to generate two optical signals to be heterodyned is based on the external modulation of a single laser source, mainly for its simplicity and tunability in frequency. Moreover, as the heterodyned signals are issued from the same laser source, they are advantageously coherent, thereby resulting in reduced phase noise. Many variants of this technique were studied achieving different multiplication factors i.e the ratio between the frequencies of the RF output signal and that of the RF input signal. A frequency doubler based on Mach-Zehnder modulators (MZM) was first demonstrated in 1992 [13]. Then, higher multiplication factors (4 and 6) were achieved [14-20]. In order to reduce the costs and use low-frequency components, some techniques wherein $\mathrm{RF}$ input frequency is multiplied by a factor of 8 were studied [21-23]. These techniques usually use optical Notch filters to suppress optical carriers or RF filters to suppress unwanted harmonics that arise from heterodyning, otherwise the

\author{
Trevor Hall \\ Centre for Research in Photonics, PTLab, \\ University of Ottawa, 800 King Edward Avenue, \\ Ottawa, Ontario K1N 6N5, Canada
}

suppression ratio would be limited. Moreover, such techniques rely on MZMs that need DC bias and whose half-wave voltage $\left(\mathrm{V}_{\pi}\right)$ depends on the frequency, thus hindering the frequency tunability of the system. In addition, these systems need control circuits to readjust DC bias voltage, which shifts or drifts during operation time of modulators.

In this paper, we propose, by simulation, a filterless method without any DC bias to optically generate millimetre-wave signals, using an input RF signal at a low frequency that will be naturally multiplied by a factor of 8 at the output of the system with a suppression ratio of $50 \mathrm{~dB}$.

\section{SiMULATION SETUP AND RESUlTS}

The proposed system setup was simulated under VPI TransmissionMaker ${ }^{\mathrm{TM}}$ as illustrated in Fig. 1. This system is based on the use of four optical phase modulators (PM) arranged in parallel. Each PM has one RF input and one optical input but with no input for DC bias. In this setup, a continuous wave optical signal provided by a laser source is split in four parts, so that each part is injected at the optical input of each PM.

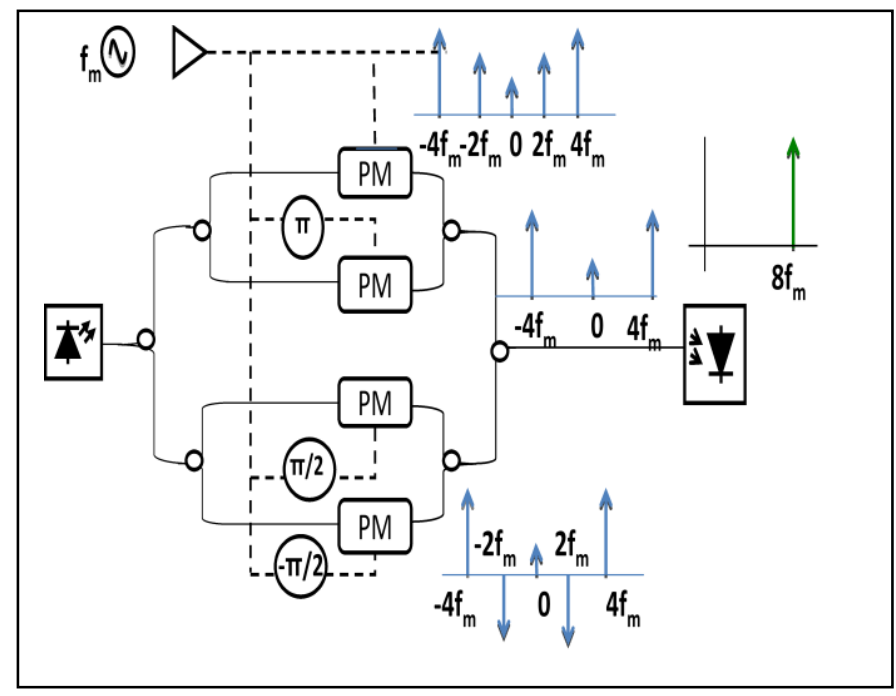

Fig. 1. Setup of an optical millimetre-wave generator by multiplication by a factor of 8 , as simulated under VPI Transmission Maker ${ }^{\mathrm{TM}}$

An input 7.5 GHz RF signal $\left(\mathrm{f}_{\mathrm{m}}\right)$ is split into four signals with equal powers. As depicted in Fig. 1, these four signals are then phase-shifted with respect to each other, as follows: the second signal is shifted by $\pi$ with respect to the input signal, the third by $\pi / 2$ and the third by $3 \pi / 2$, all of which are injected 
to the RF input of the four phase modulators respectively. The outputs of the four optical modulators are then combined together (Fig. 1) to produce an optical field at the input of the photodiode, whose amplitude $\mathrm{E}$ is given by the following formula:

$E=1 / 2(1-\alpha) E_{0} \sum_{n=-\infty}^{+\infty} J_{4 n}\left(\varphi V_{R F}\right) \cdot\left\{\cos \left(\omega_{0} t+4 n \omega_{M} t\right)+\cos \left(\omega_{0} t-4 n \omega_{M} t\right)\right\}$

With, $\quad E_{0}$ Amplitude of the optical signal

$\alpha \quad$ Insertion loss

$\omega_{\mathrm{M}}$ Angular frequency of electrical signal

$\omega_{0}$ Angular frequency of optical signal.

With the above configuration, harmonics of orders $\pm 1, \pm 2$, \pm 3 are suppressed at the input of the photodiode. Thus, the optical signal is composed out of $\pm 4^{\text {th }}$ order harmonics situated at $30 \mathrm{GHz}$ symmetrically around the optical carrier, as shown in the optical spectrum represented in Fig. 2. This signal is then injected to the photodiode.

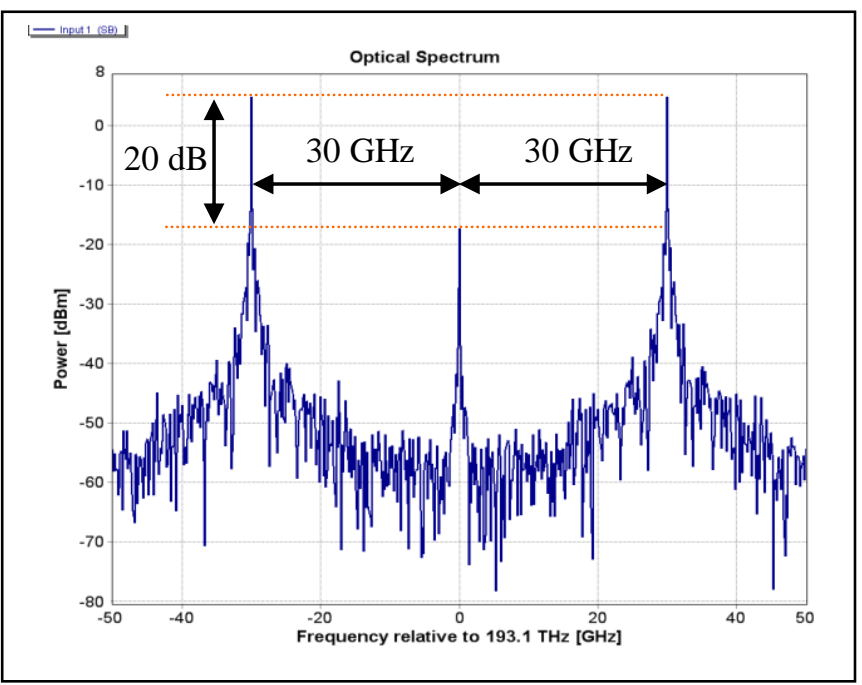

Fig. 2. Simulated optical spectrum at the input of the photodiode

According to simulations and mathematical calculations, the optical carrier should be reduced, in order to maximize the power of the $60 \mathrm{GHz} \mathrm{RF}$ signal at the output of the photodiode and minimize the amplitude of unwanted harmonics. This is done by minimizing the value of the zero-order Bessel function $\left(\mathrm{J}_{0}\right)$ while maximizing the value of the $4^{\text {th }}$ order of the same function $\left(\mathrm{J}_{4}\right)$. The value of the Bessel function order depends on the value of the RF input power as shown in Fig. 3.

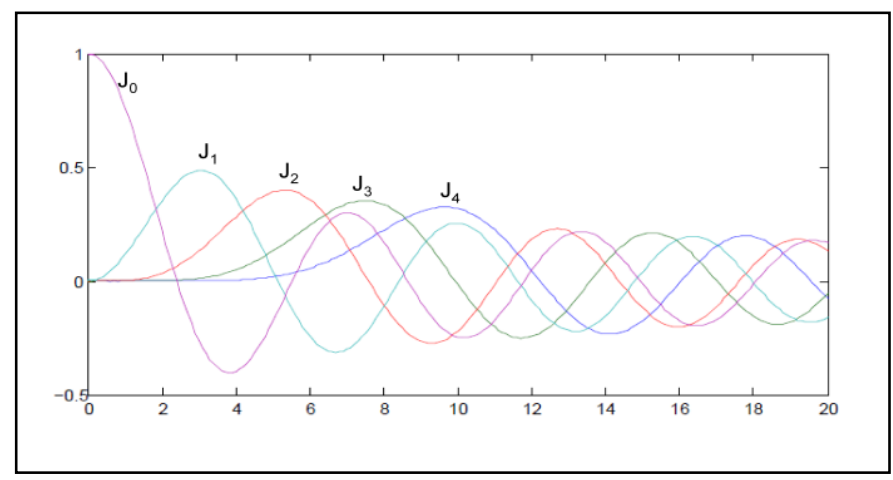

Fig. 3. Bessel function for different orders
With the proposed model, the optical carrier is rejected by $20 \mathrm{~dB}$ (Fig. 2). After photo-detection, the electrical spectrum is composed of an RF signal at $60 \mathrm{GHz}$ with a harmonics suppression ratio of $50 \mathrm{~dB}$ with respect to $30 \mathrm{GHz}$ harmonic (Fig. 4). Even though the optical carrier is not completely suppressed as we did not use any optical filter, an electrical suppression ratio of $50 \mathrm{~dB}$ is obtained, without any RF filtering either.

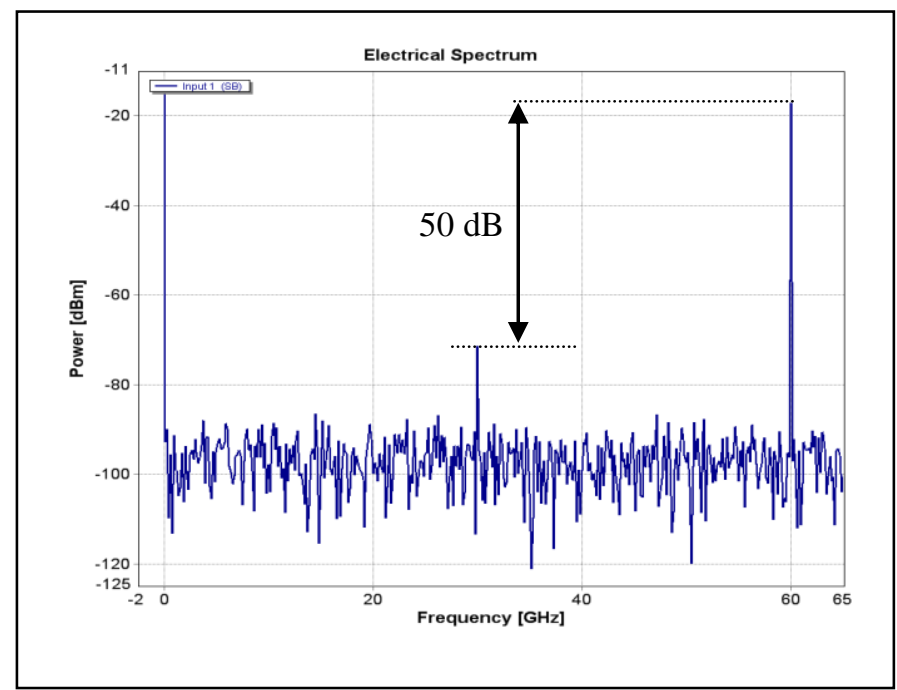

Fig. 4. Simulated electrical spectrum at the output of the photodiode

These results are obtained in ideal conditions. In practice, as RF couplers are used [24-25], power imbalance (due to the errors in the splitting ratio) and phase errors in hybrid couplers can occur. To study the impact of power imbalance, the amplitude of the four harmonics $(15 \mathrm{GHz}, 30 \mathrm{GHz}, 45 \mathrm{GHz}, 60$ $\mathrm{GHz}$ ) is presented for a splitting ratio comprised between $50 \%$ $50 \%$ to $60 \%-40 \%$ as shown in Fig. 5. If there is no imbalance between the branches (50\%-50\%), a harmonic suppression of $50 \mathrm{~dB}$ is achieved. With a splitting ratio of $51 \%-49 \%$, the suppression ratio reduces to $20 \mathrm{~dB}$, due to the $45 \mathrm{GHz}$ harmonic that becomes important.

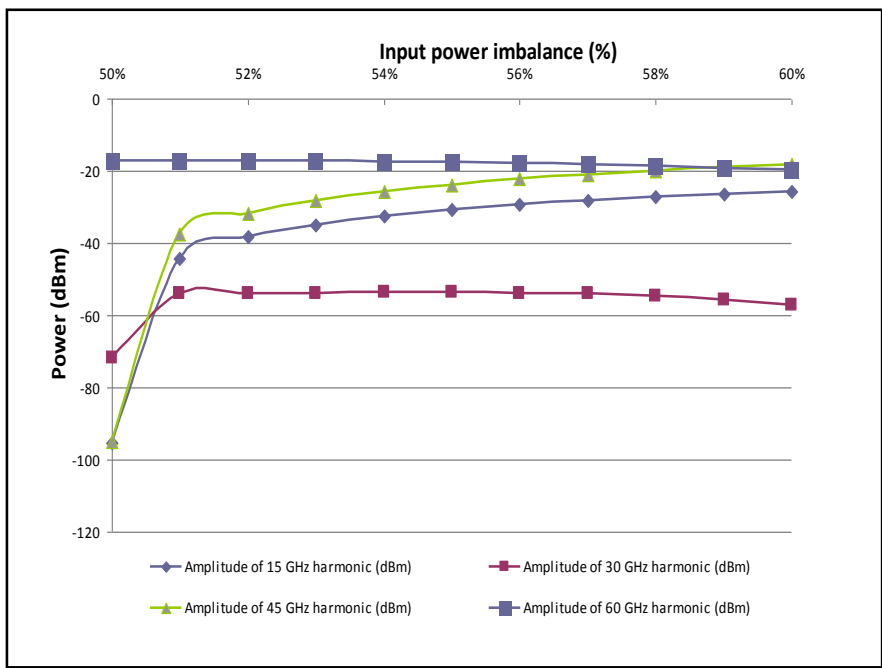

Fig. 5. Impact of input power imbalance on the generated harmonics

To study the impact of phase errors on this system, a phase error of \pm 5 degree is introduced in the simulations. In Fig. 6, the impact of a phase error from 0 to 5 degree is presented. For a negative phase error ( -5 to 0 degree), the behaviour is symmetric. With a phase error of 0.5 degree, a suppression 
ratio of more than $30 \mathrm{~dB}$ is obtained. With a phase error of more than 2 degrees, the suppression ratio starts to become less than $20 \mathrm{~dB}$.

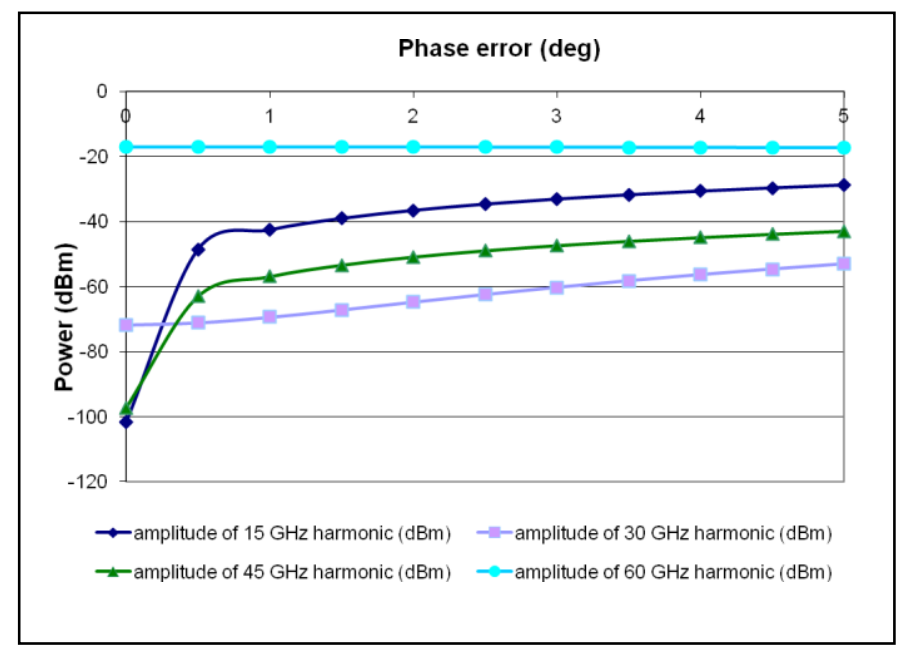

Fig. 6. Impact of the phase error on the generated harmonics

\section{CONCLUSIONS}

The proposed millimetre-wave generator can be easily tuned by adjusting its input RF frequency that is fed to the optical phase modulators. Furthermore, it is filterless in that it does not require any form of filtering (neither optical nor RF) and does not need any DC bias. This system enables to generate a $60 \mathrm{GHz}$ signal by multiplying the frequency of an input RF signal $(7.5 \mathrm{GHz})$ by a factor of 8 , with a harmonic suppression ratio of $50 \mathrm{~dB}$ if no phase error or power imbalance is considered.

Sensitivity to phase errors, and input power imbalance were simulated showing that with $2 \%$ of power imbalance or with 2-degree phase errors, a suppression ratio of $20 \mathrm{~dB}$ can still be obtained. Experimental work including spectral analysis and phase noise measurements will be carried out shortly in order to confirm these results.

\section{REFERENCES}

[1] J. Yao, "Microwave Photonics", Journal of Lightwave Technology, Feb. 2009, vol. 27, no. 3, pp. 314-335.

[2] T. Hall, R. Maldonado-Basilio, S. Abdul-Majid, J. Seregely, R. Li, I. Antoine-Pérez, H. Nikkhah, F. Lucarz, J.L De Bougrenet De La Tocnaye, B. Fracasso, P. Pajusco, C. Karnfelt, D. Bourreau, M. Ney, R. Guemri, Y. Josse, H. Liu, "Radio-over-fibre access for sustainable digital cities", Annales des Télécommunications, Jan. 2013

[3] R. Guemri, H. Liu, I. Jäger, D. Bourreau, C. Kärnfelt, F. Lucarz, "Radio-over-Fibre transmission of multiple wireless standards for digital cities: exploiting the new tramway infrastructure", $3^{\text {rd }}$ International Conference on Access Networks, June 2012.

[4] C. Kärnfelt, M. Ney, D. Bourreau, A. Bikiny, G. Guevel, Y. Paugam, F. Gallee, S. Meyer, J. Guillory, A. Pizzinat, B. Charbonnier, O. Bouffant, G. Delas, H.W. Li, E. Tanguy, M. Brunet, G. Lirzin, A. Chousseaud, C. Algani, A.L Billabert, J.L Polleux, C. Capena, G. Gougeon and V. Gouin, "A $60 \mathrm{GHz}$ radioover-fiber home area network project", International Symposium on Green Radio-over-Fibre and All-optical Technologies for Wireless Access Networks GROWAN, 15-17 June 2011.

[5] H. Liu, C. Kärnfelt, F. Lucarz and D. Bourreau, "Pico-cellular system using radio-over-fibre technology for wireless high bit rate communications", International Symposium on Green Radio-over-
Fibre and All-optical Technologies for Wireless Access Networks, 15-17 June 2011.

[6] X. Chen, Z. Deng, and J. P. Yao, "Photonic generation of microwave signal using dual-wavelength single longitudinal mode fiber ring laser," IEEE, Microwave Theory and Techniques, Feb. 2006, vol.54, no. 2, pp. 804-809.

[7] U. Gliese, T. Nielsen, M. Bruun, E. Christensen, K. Stubkjaer, S. Lindgren, and B. Broberg, "A wideband heterodyne optical phase locked loop for generation of 3-18 GHz microwave carriers," IEEE Photonics Technology Letters, Aug. 1992, vol. 4, no. 8, pp. 936938.

[8] L. Goldberg, H. Taylor, J. Weller, and D. Bloom, "Microwave signal generation with injection locked laser diodes," Electronics Letters, Jun. 1983, vol. 19, no. 13, pp. 491-493.

[9] A. Bordonaalli, C. Walton, and A. Seeds, "High-performance phase locking of wide linewidth semiconductor lasers by combined use of optical injection locking and optical phase-lock loop," Journal of Lightwave Technology, Feb. 1999, vol. 17, no. 2, pp. 328-342.

[10] Q. Wang, F. Zeng, H. Rideout, and J. Yao "Millimeter-wave generation based on four-wave mixing in an SOA", Microwave Photonics, 2006, pp. 1-4.

[11] L. Xu, C. Li, S. Lo and H. Tsang, "Millimeter wave generation using four wave mixing in silicon waveguide", OptoElectronics and Communications Conference (OECC), 2010, pp. 860-861.

[12] M. Junker, T. Schneider, K. Lauterbach, R. Henker, M. Ammann and A. Schwarzbacher, "High Quality Millimeter Wave Generation via Stimulated Brillouin Scattering", Lasers and Electro-Optics, 2007, pp. 1-2.

[13] J. O'Reilly, P. Lane, R. Heidemann, and R. Hofstetter, "Optical generation of very narrow linewidth millimetre wave signals," Electronics Letters, 1992, vol. 28, no. 25, pp. 2309-2311.

[14] G. Qi, J. P. Yao, J. Seregelyi, S. Paquet, and C. Belisle, "Generation and distribution of a wide-band continuously tunable millimeter-wave signal with an optical external modulation technique," IEEE Microwave Theory and Techniques, Oct 2005, vol. 53, no. 10, pp. 3090-3097.

[15] J. Zhang, H. W. Chen, M. H. Chen, T. L. Wang, and S. H. Xie, "A photonic microwave frequency quadrupler using two cascaded intensity modulators with repetitious optical carrier suppression," IEEE Photonics Technology Letters, Aug 2007, vol. 19, no. 13-16, pp. 1057-1059.

[16] C. T. Lin, P. T. Shih, J. Chen, W. Q. Xue, P. C. Peng, and S. Chi, "Optical millimetre-wave signal generation using frequency quadrupling technique and no optical filtering," IEEE Photonics Technology Letters, June 2008, vol. 20, no. 9-12, pp. 1027-1029.

[17] J. Yu, Z. Jia, T. Wang, and G. Chang, "Centralized lightwave radio over-fiber system with photonic frequency quadrupling for high-frequency millimeter-wave generation", IEEE Photonics Technology Letters, Oct. 2007, vol. 19, no. 19, pp. 1499-1501.

[18] J. P. Yao and H. Chi, "Frequency quadrupling and upconversion in a radio over fiber link," Journal of Lightwave Technologies, Aug. 2008, vol. 26, no. 15 .

[19] M. Mohamed, X. Zhang, B. Hraimel and K. Wu, "Frequency sextupler for millimeterwave over Fiber systems", Optics Express, June 2008, vol. 16, no. 14, pp. 10141-10151.

[20] S. L. Pan and J. P. Yao, "Tunable sub-terahertz wave generation based on photonic frequency sextupling using a polarization modulator and a wavelength-fixed notch filter", IEEE Microwave Theory and Techniques, Jul. 2010, vol. 58, no. 7, pp. 1967-1975.

[21] Y. Zhang and S. Pan, "Experimental Demonstration of Frequency-Octupled Millimeter-wave Signal Generation Based on a Dual-Parallel Mach-Zehnder Modulator", Microwave Workshop Series on Millimeter Wave Wireless Technology and Applications (IMWS), Sept. 2012, pp.1-4.

[22] J. Ma, X. Xin, J. Yu, C. Yu, K. Wang, H. Huang, and L Rao "Optical millimeter wave generated by octupling the frequency of the local oscillator", Journal of Optical Networking, 2008, vol. 7, no. 10 , pp. 837-845. 
[23] W. Li, and J. Yao, "Microwave Generation Based on Optical Domain Microwave Frequency Octupling", IEEE Photonics Technology Letters, Jan. 2010, vol. 22, no. 1, pp. $24-26$.

[24] B. Della, E. Daniel, C. Person, D. Bourreau, S. Toutain, "High Performance Lange Coupler", Electronics Letters, Oct. 1992, pp. 1997-1998.

[25] V.K. Velidi, G.Shankar, K. Divyabramham, S. Sanyal, "Compact coupled line quadrature hybrid coupler with enhanced balance bandwidth", Applied Electromagnetics Conference (AEMC), Dec. 2011, pp. 1-4. 